Article

\title{
Fans' Perceptions towards Video Assistant Referee (VAR) in the English Premier League
}

\author{
Tommy Hamsund ${ }^{1}\left(\mathbb{D}\right.$ and Nicolas Scelles ${ }^{2, *}$ (1) \\ 1 Sortland High School, Eidsfjordveien, 208, 8415 Sortland, Norway; Tommy.Hamsund@hotmail.com \\ 2 Department of Economics, Policy and International Business, Manchester Metropolitan University, \\ Business School, All Saints Campus, Oxford Road, Manchester M15 6BH, UK \\ * Correspondence: N.Scelles@mmu.ac.uk; Tel.: +44-(0)161-247-3949
}

Citation: Hamsund, Tommy, and

Nicolas Scelles. 2021. Fans'

Perceptions towards Video Assistant Referee (VAR) in the English Premier League. Journal of Risk and Financial Management 14: 573. https:// doi.org/10.3390/jrfm14120573

Academic Editor: Hannes Winner

Received: 29 October 2021

Accepted: 24 November 2021

Published: 28 November 2021

Publisher's Note: MDPI stays neutral with regard to jurisdictional claims in published maps and institutional affiliations.

Copyright: (c) 2021 by the authors. Licensee MDPI, Basel, Switzerland. This article is an open access article distributed under the terms and conditions of the Creative Commons Attribution (CC BY) license (https:// creativecommons.org/licenses/by/ $4.0 /)$.

\begin{abstract}
The video assistant referee (VAR) in association football was developed to help on-field referees judge potentially game-changing decisions correctly by reviewing video evidence in real time. VAR was implemented by the English Premier League (EPL) ahead of the 2019/20 season. Despite its potential benefits, VAR also presents the risk of not being well perceived by fans. This article aims to investigate fans' perceptions towards VAR in the EPL. Total of 1350 EPL fans from different age groups above 18 years old completed an online survey on their opinion of VAR and changes they felt would make VAR better. The majority of fans were happy for VAR to continue being used in the EPL, but expressed that changes need to be made in terms of how VAR is being used by on-field referees and to assess certain situations. All age groups were generally positive towards the idea of using technology in the EPL to support referee decisions and provide more information to in-stadium fans, but younger age groups showed significantly more positive perceptions than their older counterparts. Implications include advice for the EPL to make changes according to fans' opinions and to develop frameworks for making changes with fans as stakeholders in mind.
\end{abstract}

Keywords: video assistant referee (VAR); fans' perceptions; English Premier League; changes; age groups

\section{Introduction}

The video assistant referee (VAR) in association football is a tool developed by the Royal Dutch Football Association (KNVB) to help on-field referees judge potentially gamechanging decisions correctly by reviewing video evidence from multiple angles immediately after situations have taken place (KNVB n.d.). After a successful testing period, VAR was approved by The International Football Association Board (IFAB) by unanimous vote on 3 March 2018 (IFAB 2018). After initial testing in domestic cup competitions, the English Premier League (EPL) implemented VAR into the league ahead of the 2019/20 season, with the intention that VAR would only be used to correct clear and obvious errors such as missed incidents, penalty decisions, incidents that may warrant a red card and incidents where a player's identity has been mistaken (Premier League 2019a). In its first season, VAR has been used in all of the 380 games played out in the 19/20 EPL-season and has seen 109 goals affected by the use of VAR (Johnson 2020), of which some decisions have been deemed controversial. Examples include three controversial penalty decisions in round 34, which prompted a suggestion from former footballer Tim Cahill to add a former player to the VAR team to help the referees better understand player movements (BBC 2020).

From a business and managerial perspective, it is important to understand how fan experience is affected by VAR. Fans may be subject to an "illusion" of how VAR affects time expenditure in a game. According to Augste and Cordes (2016), more than 30 minutes of playtime in a game can be lost due to time spent doing throw-ins, free kicks and goal kicks, but due to this "always" being a part of the game, no one really notices unless it is an obvious attempt to waste time. Reviewing VAR evidence does not take up anywhere 
near the same time of a game when compared to set pieces, but since this a rather new phenomenon, fans attending in the stadium tends to notice it more, especially in stadiums where big screens are not installed, as the consumers often do not know what situation is being reviewed, causing confusion and frustration whenever a VAR situation takes up a few minutes (Spitz et al. 2021). This confusion and frustration might be reduced as stadium attendees will gradually get used to the presence of VAR in football, but as it stands, watching the game from home provides a much better opportunity to understand what is happening during a VAR review, and why, when compared to stadiums without big screens. These elements underline the risk of VAR not being well perceived by fans, at least for those attending in stadium. This risk may lead to the subsequent risk of fans being less willing to attend games in stadium, which may have a negative economic and financial impact on clubs.

Despite the importance of understanding how VAR affects fan experience, this topic has received limited academic attention. In line with this gap in the literature, the aim of this research was to investigate fans' perceptions towards the use of VAR in the EPL. The overarching question was: How do fans perceive the way VAR is used in the EPL? Two subsequent research questions were formulated: Do fans perceive that VAR has a more positive impact on some dimensions than others in the EPL? (research question 1); 2. Does age impact fan perceptions on the use of VAR in the EPL? (research question 2). The first research question aimed to help decision-makers understand what the benefits of VAR are from the fans' perspective, be able to communicate on these benefits, and prioritise areas for further improvement based on the dimensions perceived by fans as having a less positive impact. The second research question was constructed based on the assumption that younger fans may be more open to the use of a technological tool such as VAR, due to the technology-driven nature of their generation (Yim et al. 2021). In a context where sport marketing practitioners are concerned about decreasing fan attendance in future generations and among Millennials (Yim et al. 2021), it is important to understand how they perceive the use of tools such as VAR.

\section{Literature Review}

\subsection{How VAR Modifies the Game}

The current literature on VAR mostly focuses on the impact of the technology on the game itself, which can eventually affect fan experience. Lago-Peñas et al. (2019) showed that the introduction of VAR into the German Bundesliga and Italian Serie A had seen more time being added in the first half of games, as well as reduced the number of offside-calls, fouls and yellow cards. Their findings suggested that VAR did not have a substantial effect on football. This is supported in Errekagorri et al. (2020), who used data from the Spanish La Liga and found that more VAR checks equalled more goals and that total distance covered by players decreased when there was more than one VAR check. They also found evidence that total playing time had increased in games with two or three VAR checks, but that effective playing time decreased when there were several VAR checks in a game. However, they also specified that these changes did not significantly impact the games. These studies utilised concrete statistical data from a large sample of matches and did not take the "human" factor into account in how the technology affects consumers, including in-stadium fans. A study conducted on the Chinese Super League (CSL) drew comparisons between games with and without the presence of VAR and found that offside calls and fouls had dropped significantly, as well as a significant increase in total minutes played, concluding that the home advantage observed before VAR had decreased (Han et al. 2020). The findings of this study were in contrast to the findings in both Lago-Peñas et al. (2019) and Errekagorri et al. (2020), but only shared a methodological approach to Lago-Peñas et al. (2019). Errekagorri et al. (2020) did not use data from before VAR was implemented, but rather used grouped data according to the number of VAR interventions during the games, not differentiating between the type of VAR intervention (offside, penalty, red card, etc.). 
The only research paper where VAR in the EPL was mentioned is in Ludvigsen (2020), who predicted that VAR would be welcomed by some fans, but would also be subjected to criticism due to VAR being a tool that removes many contentious decisions that fans typically enjoy debating, hence making EPL football predictable. Video refereeing in other sports has been criticised heavily (Nafziger 2004). However, Nafziger (2004) argued that the potential legal consequences of a referee refusing to use the technology may cause additional controversy and the decision-aid technology should therefore be utilised as intended. The idea of introducing video refereeing into football was present long before the technology was developed, and it was envisioned that the technology would disrupt the flow and pace of the game of football, rather than improving it (Svantesson 2014; Nafziger 2004). These ideas seem to reflect some of the perceptions of players and experts after the introduction of VAR into football, but it is important to note that the technology is being recognised as effective by some, and that the time-consumption is worth it if decisions are made correctly as a result (Martin 2018; BBC 2018). However, the law-makers responsible for VAR have stressed that the technology should only be used for clear and obvious errors, and the referee should generally rely on their own interpretation and only use the technology in very ambiguous situations (BBC 2019). The opinion that refereedecisions should be based on their own interpretation is reported by multiple authors (Nlandu 2012; Svantesson 2014), and seems to be a key argument towards the use of decision-aid technology in sport. In Singh (2012), it was argued that introducing linetechnology would be too expensive and impractical to implement at all levels of football. GLT is only present in some of the biggest football leagues in world football and is yet to expand to include "smaller" football leagues (Hawk-Eye).

\subsection{Consumer Perceptions towards Decision-Aid Technology}

Football fans have a strong and emotional connection to the objects that produce the content they consume, such as football teams and players (Samra and Wos 2014). A fan is a consumer of organised sports (Hunt et al. 1999), and come in many different forms depending on their level of devotion. The loyal fan will spend significant time and money on following their sport, team or athlete, while the casual spectator will spend less money and feel less connected to a specific entity in sport, hence why the loyal fan is more important to sport organisations (Mastromartino et al. 2017). The most important consumer group for the business of a sport club is the fan due to the fact that without them, there would be no demand for televised sport, and it would be a difficult task for sport clubs to attract sponsors if no one was there to see their product (Da Silva and Casas 2017). Understanding fan behaviour is crucial for sport organisations to ensure that they can evolve alongside the ever-evolving wants and needs of sport fans (Dwyer et al. 2016). Research on fan experience suggests that noise and crowd size are the most important factors when fans are assessing their own in-stadium experience (Wilkie 2008). However, as more factors that may affect crowd experience are added into sport, such as decision aid technology, it is necessary to conduct new research on crowd experience with these factors in mind. According to Singh (2012), removing the enjoyment that fans feel when debating contentious goals might reduce atmosphere with the introduction of decision-aid tools such as Goal Line Technology (GLT).

The amount of research on consumer perceptions towards decision-aid technology in sport is very limited and only two research papers were deemed relevant for direct comparison with this research. They may provide some useful insight into the general perceptions of consumers and include Winand and Fergusson (2018), who explored consumer perceptions towards the introduction of GLT into football and Stoney and Fletcher (2020), who explored consumer perceptions towards the use of the Television Match Official (TMO) in rugby. The findings of Winand and Fergusson (2018) were that fans trusted the GLT technology when used and supported the use of it, but also that fans did not enjoy the use of GLT due to the technology eliminating the tension surrounding a contentious decision, hence reducing the satisfaction of fans due to their enjoyment of debating such 
contentious decisions. They also found that fans did not support the idea of adding further aid-decision tools into football, recommending that key stakeholders are consulted when considering adding or changing rules of decision-aid technology that may affect their experience. These findings imply that the idea of introducing VAR into football is opposed by fans, depending on how it affects their viewing experience.

Research on consumer perceptions towards the use of the TMO in Rugby Union games uncovered that football fans did not take issue with the use of the technology, but rather with how information was relayed to them in-stadium (Stoney and Fletcher 2020). The findings of this article suggest that fans will have a better experience when information is relayed to them as decisions are being made, and not just after. The current system in Rugby Union games is similar to how the EPL conducts VAR checks, with fans being informed of what is being checked through information on big screens in the stadiums, with replays being played to inform in-stadium fans on overturned decisions (Premier League 2019b).

\subsection{Differences between Age Groups}

Research on consumer perceptions towards use of decision-aid technology looking at the impact of age groups is very rare at this point in the literature. Both Winand and Fergusson (2018) and Stoney and Fletcher (2020) included age groups in their sample description but did not report any difference in opinion between age groups. This suggests that there might not be any difference in opinion from a young to an older fan, but this is unclear due to the lack of research available. One could argue that millennials should be more likely to accept technological changes in football due to the technology-driven nature of their generation (Yim et al. 2021). Younger adults tend to use a wider spread of technological inventions than older adults (Olson et al. 2010), but older adults are generally open-minded when presented with an opportunity to learn using and understanding modern technology (Vaportzis et al. 2017). These findings should be considered relevant when discussing technology in football and may be the reason for why previous research on perceptions towards decision-aid technology in sport has not uncovered any differences across age groups.

\section{Methodology}

\subsection{Research Method and Data Collection}

A quantitative approach was used in this study. More specifically, a survey was conducted with football fans ( $\mathrm{n}=1353$ respondents). The use of a survey is considered a standard research method due to the regular need of reaching out to mass target populations, in this case sport fans, and how surveys are useful to describe characteristics, perceptions and the behaviour of the target populations (Andrew et al. 2020). The wish to make a generalisable description about the perceptions of a particular population, being the football fans, makes the choice of a deductive approach logical due to the questionnaire containing closed questions with set answer options. This fits the characteristics described in Janzen et al. (2015), who stated that a deductive approach assumes that a sound measurement of values are rooted in a theory that is predetermined. This approach ensures high predictability as well as producing results that can be easily interpreted (Veal 2018).

The survey method matched the usage of a Likert scale in similar research such as Winand and Fergusson (2018) and Stoney and Fletcher (2020), who both used a 7-point Likert scale rather than the 5-point scale which was used for this study. A 7-point scale was deemed excessive for this study. According to Revilla et al. (2013), 5-point Likert scales should produce better quality of data. Moreover, a 7-point Likert scale is considered more suitable to use in projects where the participants are mostly students due to the assumption that students have higher cognitive ability than members of the general public (Weijters et al. 2010). This makes a 5-point Likert scale more suitable for this study since it did not reach out to just students, but anyone who watches football and is above 18 years of age. The Likert scale is considered a strong tool to use in surveys due to its widespread 
use, making it a comfortable tool for researchers and respondents, as they are likely to have encountered the design in previous surveys (Cooper and Johnson 2016). According to Ponto (2015), the usage of a survey can be useful to explore consumer patterns, in this case fans' perceptions towards the addition of VAR into EPL football, and how this addition will affect their behaviour in the future.

Due to the authors wishing to produce generalisations of a population, a quantitative method of using an online questionnaire was considered a logical choice. Questionnaires are, however, limited by their predetermined questions and limited answer options (Bell et al. 2019). A different approach might have uncovered more information from participants who possess more knowledge than others, but using interviews was deemed too time-consuming and not consistent with the objective to produce generalisations. An online questionnaire was considered to be the most effective method to acquire a large sample group, consistent with the findings of Duffy et al. (2005), who suggested that an online questionnaire would be more attractive than interviews for participants due to its convenient nature. With this method, participants can complete the questionnaire when they see fit, rather than having to plan a specific time to be interviewed.

\subsection{Participants}

Participants were recruited through social media platforms, specifically Facebook and Twitter. A social media post was posted in Norwegian and British Facebook groups dedicated to EPL fans of no specific team-affiliation, as well as on Twitter, where there were no geographical filters present. Participants were informed of the nature and purpose of the study as well as inclusion criteria, which were that they followed EPL actively and were above 18 years of age. If interested, participants were provided with a link to the survey, provided they met the inclusion criteria. Preliminary and post-completion statements were included to inform the participants of the purpose of their participation as well as inform them on their right to withdraw from the study.

The sample size was 1353, of which 305 were aged 18-23, 360 aged 24-29, 405 aged 30-39, 200 aged 40-49 and 83 above 50 years of age. Of the entire sample size, 1350 participants completed all 15 questions, while 3 participants did not answer the final question for reasons unknown and were excluded from the study. No participants asked to be removed from the survey after completion. The authors' university ethics guidelines state that participants should be at least 16 years of age. However, having only adults participating in this study was deemed desirable as to avoid any potential conflicts in terms of the need to acquire parental permission for non-adults. Age of majority for most EU countries is 18 (FRA n.d.). For this reason, only people over 18 years of age were allowed to participate in the study. Consent forms were not included in the survey, as consent is implied when returning a questionnaire, also according to the university ethics guidelines. Due to the inclusion criteria and the large sample size, the results should be generalisable for a larger population (Queirós et al. 2017).

\subsection{Survey Contents}

The authors' university online survey system, Jisc, was used to construct and perform the survey. This tool was considered suitable due to the simplicity it offered in constructing, distributing, and analysing an aesthetically pleasing survey that was easy for respondents to navigate around and answer questions without any advertisement or other potentially distracting content present on the screen. The survey started with a preliminary question that asked the participants to choose their age group, of which the range was explained in the participant section. The 15 statement questions that followed explored different issues with VAR in the EPL, with all 15 questions addressing both research questions 1 and 2. The questionnaire can be viewed in its entirety in Table S1 in the Supplementary Material. The absence of peer-reviewed literature on VAR made replication of previous research impossible, hence why most questions were constructed in reference to common themes identified by observing perceptions displayed by different fan groups across social media 
platforms. These questions covered aspects such as fairness (Q1), understanding (Q2), time needed (Q3 and Q11), different dimensions relevant to the review of decisions (Q4, Q5, Q8, Q10, Q13 and Q14), impact on fans' interest (Q6), supplement to goal-line technology (Q7) and potential removal until perfected (Q15). Two other questions were constructed in reference to how other sports use video refereeing. These questions included the presence of a screen in stadia like in rugby (Q9), and the opportunity to protest decisions based on technology like in tennis (Q12). No time limit was set to complete the survey other than that it was completed before the closing date.

\subsection{Data Analysis}

The gathered data were prepared and validated using the data validation tool in Microsoft Excel. The countif-function was used to check for missing data. Data were further analysed using Microsoft Excel for the purpose of calculating mean values and standard deviations across age groups and responses for each question. All of the participants answered the same 15 questions, which provided the means to conduct comparisons both between questions involving the same participants through one-way analyses of variance (ANOVAs) with repeated measures and dependent groups (research question 1), as well as between age groups for each question through one-way ANOVAs with independent groups (research question 2). IBM's Statistical Package for the Social Sciences (SPSS) 26 was used to perform one-way ANOVAs. Figure 1 displays the overall data analysis process.

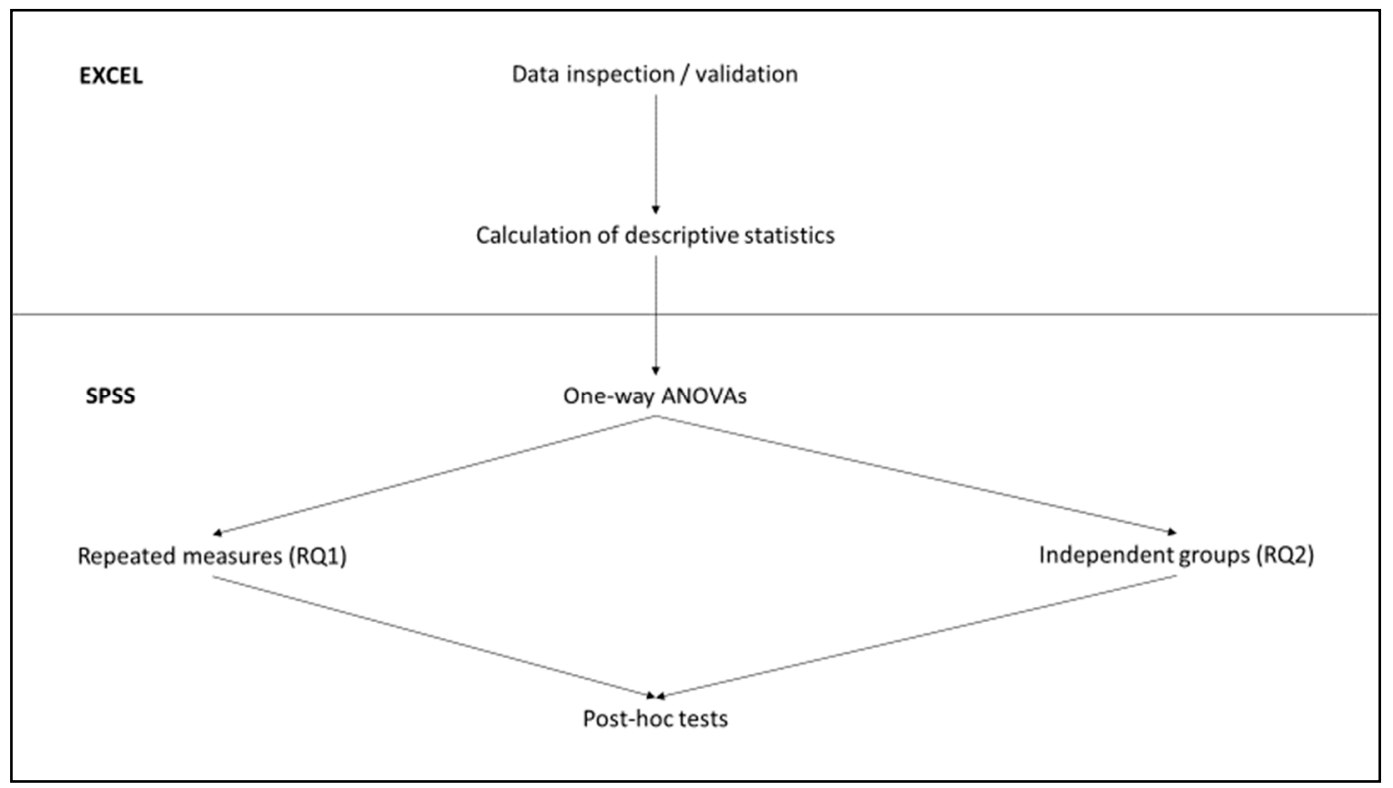

Figure 1. Overall data analysis process.

\section{Results}

\subsection{Overview}

The means and standard deviations for the 15 survey questions are presented in Table 1, with the different items ranked from the highest to the lowest average mean score. Overall, the results show that the participants agreed that changes need to be made on how VAR is used, with nine survey items displaying a mean value over 3. However, when conducting one-way ANOVAs with repeated measures and dependent groups to compare items between each other, it is worth noting that there are significant differences at the $5 \%$ level between each item except items 8 and 3, as well as items 13 and 12, in support of a positive answer to research question 1 (results available upon request). This means that the EPL could confidently prioritise the changes to be made (or the features to be retained) based on fans' perception. Table 1 also provides the results of the one-way 
ANOVAs with independent groups to compare age groups for each survey questions, with the identification of significant differences for eight out of the 15 questions. Tukey's range tests for Post-Hoc analysis were performed for all items to uncover between which age groups significant differences lie (available upon request). These Post-Hoc tests unveil some significant differences with one-tailed tests for two questions where no significant difference was originally identified through the ANOVAs, meaning that overall 10 out of the 15 questions show significant differences between age groups, in support of a positive answer to research question 2. Figure 2 provides an overview of the results.

Table 1. Survey items sorted by mean values, with standard deviations and differences between age groups.

\begin{tabular}{|c|c|c|c|c|}
\hline Question & Rank & Mean & Standard Deviation & $\begin{array}{l}\text { Difference between Age } \\
\text { Groups ( } p \text {-Value) }\end{array}$ \\
\hline The addition of VAR has made the Premier League less fair. & 14 & 2.31 & 0.917 & 0.462 \\
\hline I find it difficult to understand how VAR works. & 11 & 2.81 & 1.178 & 0.435 \\
\hline $\begin{array}{l}\text { VAR situations take up too much time of a Premier } \\
\text { League game. }\end{array}$ & 6 & 3.55 & 1.152 & $0.001 *$ \\
\hline $\begin{array}{l}\text { The on-field referee should always review VAR evidence } \\
\text { when a potentially match-changing decision has to be made. }\end{array}$ & 4 & 3.78 & 1.229 & 0.064 \\
\hline $\begin{array}{l}\text { The VAR team for each matchday should consist of several } \\
\text { expert referees who are making decisions together, rather than } \\
\text { relying on the individual interpretation of just one } \\
\text { expert referee. }\end{array}$ & 2 & 4.05 & 0.982 & $0.003^{*}$ \\
\hline $\begin{array}{l}\text { The introduction of VAR has made me less interested in } \\
\text { watching Premier League football. }\end{array}$ & 15 & 1.94 & 1.141 & 0.838 \\
\hline $\begin{array}{l}\text { VAR should be used if and when there is suspicion that the } \\
\text { goal-line technology (Hawk-Eye) has failed to perform } \\
\text { its task(s). }\end{array}$ & 1 & 4.29 & 1.021 & 0.000 * \\
\hline $\begin{array}{c}\text { The Premier League should change how VAR assesses offside } \\
\text { situations. }\end{array}$ & 5 & 3.56 & 1.103 & 0.073 \\
\hline $\begin{array}{l}\text { VAR screens should be mandatory in every Premier League } \\
\text { stadium to ensure that fans inside the stadium are thoroughly } \\
\text { informed on why a VAR decision is made. }\end{array}$ & 3 & 3.97 & 1.035 & 0.000 * \\
\hline $\begin{array}{l}\text { VAR should be able to review evidence from past situations at } \\
\text { any time during a game and potentially penalise actors of the } \\
\text { game who have broken the rules without being caught. }\end{array}$ & 8 & 3.18 & 1.336 & 0.128 \\
\hline $\begin{array}{l}\text { The introduction of VAR in the Premier League has made } \\
\text { goals less enjoyable due to almost every goal potentially being } \\
\text { subjected to a VAR review. }\end{array}$ & 7 & 3.48 & 1.225 & 0.000 * \\
\hline $\begin{array}{l}\text { Each team should be given a few opportunities per game to } \\
\text { protest VAR decisions that have been made without the } \\
\text { on-field referee reviewing video evidence, prompting a formal } \\
\text { review by the on-field referee. }\end{array}$ & 10 & 2.97 & 1.356 & 0.000 * \\
\hline $\begin{array}{l}\text { The on-field referee should be able to review VAR evidence } \\
\text { post-match to penalise actors of the game who have broken } \\
\text { the rules during a match without being caught. }\end{array}$ & 9 & 3.02 & 1.330 & $0.000 *$ \\
\hline $\begin{array}{c}\text { VAR should be used for more than just clear and } \\
\text { obvious errors. }\end{array}$ & 12 & 2.71 & 1.263 & 0.234 \\
\hline $\begin{array}{l}\text { VAR should be removed from the Premier League until the } \\
\text { system is perfected. }\end{array}$ & 13 & 2.49 & 1.307 & $0.000 *$ \\
\hline
\end{tabular}




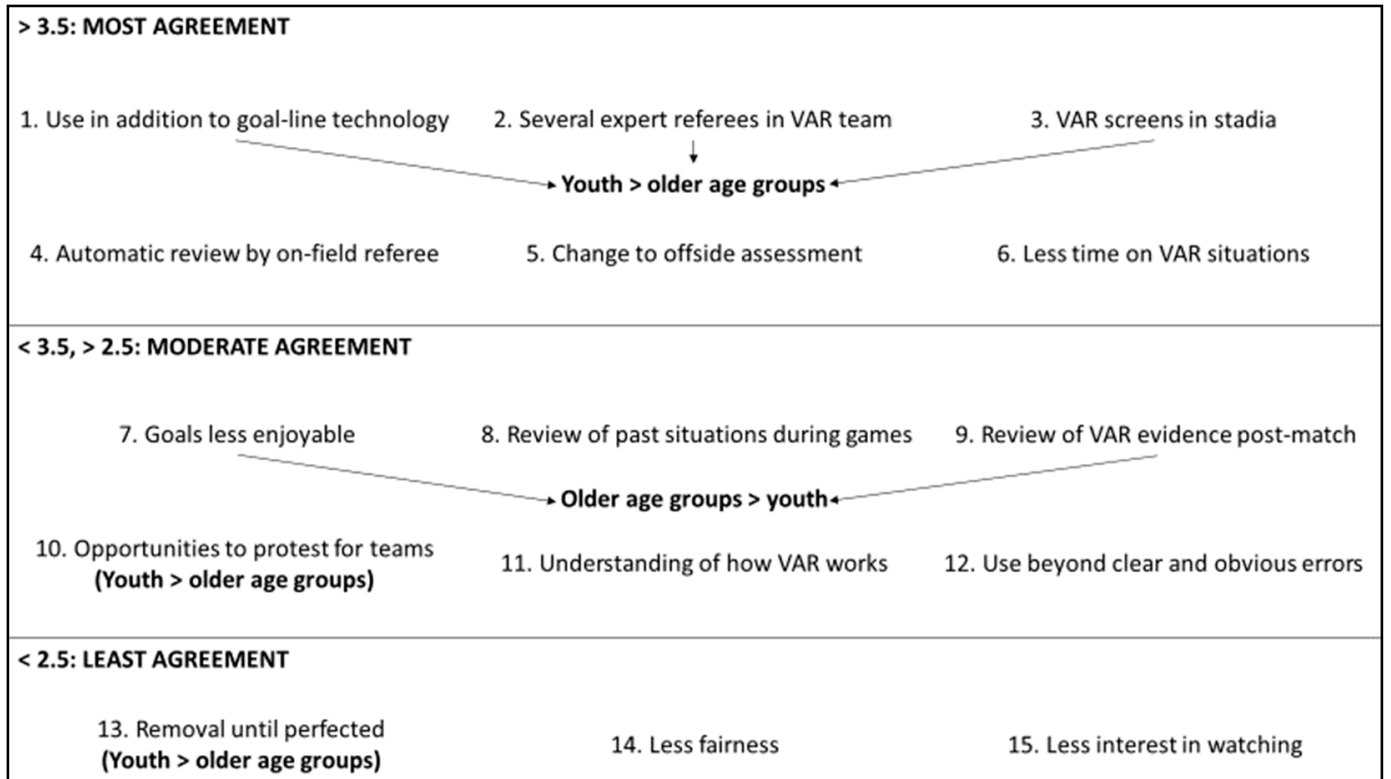

Figure 2. Overview of the results.

\subsection{Items for Which Fans Suggest a Need for Change (Mean > 3.5)}

The first-ranked item in Table 1 shows that fans agree that VAR should be used if the Hawk-eye technology has failed to do its job. The agreement was stronger for younger participants. The age group of 24-29 showed the same feelings as age 18-23 ( $p=1.000)$ but significantly stronger positive feelings compared to the three oldest age groups of age $30-39(p=0.002)$, age 40-49 $(p=0.000)$ and age above $50(p=0.000)$. These results suggest that younger fans are more positive than older fans of the use of VAR in addition to GLT and implies that the EPL should use VAR if Hawk-Eye fails to perform its task if they are to adhere to the opinion of younger fans on how VAR is used.

The second-ranked item shows that fans agree more than one expert referee should share responsibility in the VAR room during matchdays. This is consistent with the idea that subjectivity amongst referees is a problem that VAR has helped reduce, but not eradicate (Ugondo and Tsokwa 2019). No research has been conducted to see how subjectivity affects referees in the VAR room, but it is safe to assume that the phenomenon can occur with referees regardless of where they are situated. Results show that fans agree that there should be more than one referee in the VAR room, but also significant differences between age groups, as age 18-23 showed more positive perceptions towards the idea of more than one expert referee in the VAR room than age 30-39 $(p=0.003)$ and age above $50(p=0.045)$. Although significant differences were evident, these results should not be misunderstood, as all age groups did display positive perceptions towards having more than one expert referee in the VAR room. The youngest age group did agree more than other groups, but they were also above or very close to a mean value of 4.0, which means "agree".

The third-ranked item shows that fans agree that big screens should be mandatory in every EPL stadium. Although the participants generally agreed that big screens should be mandatory, there were significant differences between age groups, which showed that the age group 18-23 was significantly more positive towards the idea of installing big screens in EPL stadiums compared to age 30-39 $(p=0.037)$, age 40-49 $(p=0.000)$ and age above $50(p=0.040)$. Additionally, age $24-29$ was significantly more positive towards the idea compared to age $40-49(p=0.001)$. The findings from this item also suit the perceptions described in Yim et al. (2021), who stated that younger generations are generally more technology-driven than older generations and prefer to consume sport products through the use of technology. Besides, there is a stronger agreement from fans that big screens should be mandatory in every EPL stadium over most of the items relevant to how and the scope VAR should be used. This suggests that big screens are a more important factor. 
The fourth-ranked item shows that fans mostly agree that the on-field referee always should consult VAR evidence when a potentially match-changing decision has to be made. There were no significant differences of opinion between age groups for this item with a two-tailed test, although the youngest age group of 18-23 displayed generally more positive perceptions towards the idea (mean =3.92) than those aged above 50 (mean = 3.52), and the difference is significant with a one-tailed test $(p=0.034)$. Although these results show that fans like the idea of the on-field referee taking the final decision on potentially match-changing decisions, it is important to note that this likely would cause additional time-consumption with VAR.

The fifth-ranked item shows that the participants rather tipped in favour of agreeing that offside situations should be assessed differently rather than a neutral stance. Despite not showing any significant differences across age groups with the one-way ANOVA, Post-Hoc tests uncovered that there was a significant difference between the youngest age group of 18-23 and the oldest age of above 50, with the oldest group being more negative towards the prospect of amending the way VAR assesses offside situations $(p=0.049)$. The oldest group is also more negative than the age groups of 24-29 and 30-39, with significant differences with a one-tailed test (respectively $p=0.027$ and $p=0.035$ ).

The sixth-ranked item shows that fans were rather agreeing that VAR takes up too much time of an EPL game. There were significant differences present between age groups 18-23 and 24-29, where the younger group felt significantly less negative towards timeconsumption $(p=0.028)$ as well as the age group above 50 feeling significantly less negative towards time-consumption compared to age groups 24-29 $(p=0.011), 30-39(p=0.049)$ and $40-49(p=0.025)$. These results suggest that the youngest and the oldest group are the ones who feel the least that time consumption with VAR is a problem, tipping towards a neutral standpoint $(18-23$ mean $=3.40$ and above 50 mean $=3.21)$. This implies that these fans would rather see more time spent if the result is that the decision is made correctly.

\subsection{Items for Which Fans Are More Neutral towards a Change (Mean 2.5 to 3.5)}

The seventh-ranked item asked participants whether their enjoyment of goals reduced due to the possibility that every goal potentially can be reviewed and ruled out. The results show that the participants were slightly closer to a neutral stance than agreeing, meaning that they did not agree that goals were less enjoyable due to the introduction of VAR. The age group of above 50 showed significantly more positive perceptions towards enjoyment of goals with VAR than ages 18-23 ( $p=0.000), 24-29(p=0.001)$ and 30-39 $(p=0.000)$. There were differences compared to age $40-49$ as well, not significant with a two-tailed test but significant with a one-tailed test $(p=0.037)$.

Items ranked eight and nine were developed based on the idea that video evidence may emerge post-event or post-match to show the infringements of players and managers that went unnoticed at the time they occurred or during the game. Item eight shows results that suggest a neutral stance towards the use of VAR to review past events of a match, with no significant difference between age groups. Similarly, item nine shows a neutral stance towards the use of VAR post-match, but significant differences were found between the youngest age group 18-23 who showed significantly more negative perceptions towards the use of VAR post-match to penalise players/managers who had done something wrong compared to ages 30-39 ( $p=0.023)$, age 40-49 $(p=0.000)$ and age above $50(p=0.022)$, as well as age group 24-29 with a one-tailed test $(p=0.036)$.

Item ranked 10 explores the idea of giving each team the opportunity to contest decisions to prompt VAR reviews and shows neutral results, but significant differences between age group above 50 and the groups of age 18-23 ( $p=0.000)$, age 24-29 $(p=0.000)$ and age $30-39(p=0.023)$, as well as age $40-49$ with a one-tailed test $(p=0.043)$. These results show very large mean differences, with the youngest age group 18-23 averaging a mean score of 0.795 higher than the above 50 group. These findings suggest that the younger age groups are more positive of the idea of letting teams contest decisions, but 
their mean (3.18) is still well within the neutral spectrum and does not imply that this should be an addition into the game.

Item ranked 11 shows that members of every age group do not struggle to understand how the VAR technology works, with no significant difference present between age groups. The fact that fans understand how the technology works should be considered positive for the EPL, as it suggests that the fans have been thoroughly informed on VAR. It is important to note that these results do not represent VAR decisions, but rather the technology itself. This means that even if a consumer understands how VAR is used to assess offside- penaltyand yellow/red card-decisions, it does not mean that they will agree with the decisions due to subjectivity. Especially in-stadium fans will be unlikely to just sit quietly and agree with referee decisions against their team, even if they are correct, as they feel a responsibility to help their team by distracting the opposition and influencing the referee to judge in their team's favour (Wolfson et al. 2005).

Item ranked 12 was based on a potential change to VAR supposed to be only used for clear and obvious errors. This is because the reality of VAR being only used for clear and obvious errors has been ambiguous at best during the debut season of VAR in the EPL. The EPL has defined clear and obvious errors as situations where the on-field referee requests assistance due to not having caught/understood a situation properly (Premier League 2019b), including situations that went completely unnoticed by the referee. Yet, the term still remains unclear due to numerous controversial decisions made during the 19/20 season. These decisions cast doubt about whether all errors judged were really clear and obvious, and whether all clear and obvious errors were judged. This prompted EPL referee Mike Riley to admit that some clear and obvious errors were not judged the way they were supposed to due to lack of judgement based on little experience (Sky Sports $2019 b)$. This then birthed the idea that perhaps VAR should be used for more than just clear and obvious errors, as to avoid confusion for referees. Results showed that fans were tipping in favour of a neutral standpoint, with no significant differences between age groups, suggesting that the current usage of VAR is suitable in the eyes of fans.

\subsection{Items for Which Fans Suggest No Need for a Change (Mean < 2.5)}

Item ranked 13 presented a radical proposition to the participants by asking if VAR should be removed until the system had been perfected. Mean values suggest that fans are more in favour of keeping VAR, but there were significant differences present, showing that age group 18-23 was significantly more towards a neutral standpoint than age groups 24-29 ( $p=0.004), 30-39(p=0.001), 40-49(p=0.000)$ and above $50(p=0.000)$. Additionally, age group 24-29 was significantly more towards a neutral standpoint than age above 50 $(p=0.044)$. Age group 30-39 was also significantly more towards a neutral standpoint than age above 50 with a one-tailed test $(p=0.034)$. These findings suggest that the older the participants were, the less interested they were in removing VAR from the EPL. This shows that despite its flaws, fans consider VAR to be working to some extent, or they would have asked for it to be removed. The fact that fans support the continued use of VAR implies that the EPL has been successful in adding VAR into the league, and it is now important for the referees to get fewer decisions wrong and to optimise the reviewing process to make fans feel more involved and informed.

The results of item ranked 14 were inverted due to this item being the only question that did not involve a change or raising an issue, meaning that it was positive in nature. The results show that fans disagreed that fairness had been reduced with VAR, with no significant difference between age groups. These results suggest that VAR has succeeded in the eyes of consumers in terms of reducing major errors in making the EPL fairer, and that the technology indeed works. However, these results are not representative of actual statistics, and therefore should be completed with more evidence that VAR has made the EPL fairer as they only showcase fans' perception of fairness with VAR.

Item ranked 15 and last shows that the addition of VAR has not made fans less interested in watching EPL football, with no significant difference between age groups, 
meaning that there is a consensus across all ages from 18 to above 50 that they are still very interested in watching EPL football. The question now becomes what changes will be made to make the usage of VAR more enjoyable for fans, or rather less annoying by consuming less of the allocated 90 minutes of a game to review evidence and getting decisions right the first time.

\section{Discussion and Conclusions}

\subsection{Comparison between Related Results}

Some items in the survey provide the means for comparison between them. Such items include items nine and 10 in Table 1 . Item nine stated that VAR should be able to review evidence and advice punishments at any point during a game, while item 10 stated that the on-field referee should be able to review VAR evidence after the game and then issue punishments. Video evidence has been used post-match to review past incidents long before the introduction of VAR, for example to investigate the statements made by players during the infamous racism-incident between former Liverpool player Luis Suárez and former Manchester United player Patrice Evra (The FA 2012). The idea was therefore to measure fans' perceptions towards investigating video evidence during the game to penalise actors of the game by a red card for such things as racist comments with item nine. Alternatively, for item ten, the idea was to measure fans' perceptions towards using VAR for the same purpose but post-match, with the on-field referee being responsible for making decisions. Although participants were close to a neutral standpoint for both items, there was a significant difference between these items $(p=0.000)$, as item nine was more agreeable than item 10 for participants.

These results imply that fans are more favourable of punishments during the game than after the game. If a serious foul play has gone unpunished during the game, it is likely to be resolved by The Football Association (FA) after games. However, the idea of letting VAR take action at any point of a game seems to be more attractive for fans. As previously discussed, this could potentially be match-deciding, if perpetrators were allowed to be caught and punished during the game and not after, for incidents that originally went unnoticed. With the number of cameras and microphones inside a football stadium, racist remarks or other violations that the referee did not hear or see might be caught on tape and can in theory be used to issue cards. If for example an incident of racism occurs, an actor of the game would be sent off if the referee heard it. Thus, it can be argued that VAR should be used for the situations that the referee did not see or hear, similar to how it is used if someone uses violence without being spotted by the referee.

Items four and six in Table 1 also provide the means for comparison. Item four asked for the participants' views on use of VAR monitors by on-field referees, and item six revolved around consumer perceptions towards time consumption with VAR. When compared, the results show a significant difference $(p=0.000)$, with fans agreeing that VAR takes up too much time (mean $=3.55)$, but still want referees to use VAR monitors $($ mean $=3.78)$. The question on time consumption preceded the question on usage of VAR monitors. As such, the risk of the participants "forgetting" the question of time consumption in between questions should be quite low.

\subsection{Comparison with Previous Research}

The findings in this study show some similarities to the findings of Winand and Fergusson (2018). The authors found evidence that fans favoured the use of Hawk-Eye's GLT in football, similar to how the participants in this study stated that: they thought the EPL had become fairer as a result of VAR; they were slightly in favour of the continued use of VAR; they did not lose any interest in watching the EPL due to the addition of VAR. There were, however, differences in fans' perceptions towards the factor of enjoyment between the studies. Winand and Fergusson's (2018) findings stated that fans enjoyed football less due to GLT reducing the amount of contentious decisions. Although not measured specifically, certain items in this study measured how the experience of fans felt affected 
by VAR. This was specifically the case for the item measuring how fans experienced goals when they knew that there could always be a VAR review to overturn it right after. The results showed that fans were slightly towards a neutral standpoint. This is in contrast to how the participants in Winand and Fergusson (2018) felt that contentious goal decisions would be reduced in number due to the addition of GLT, which would lead to a reduction in enjoyment. Their study also found evidence that fans did not welcome future decision-aid technology. This was not measured in this study, but the results do show that fans are happy with how VAR is being used and are not in favour of removing it. This suggests that the perceptions against more decision-aid technology in Winand and Fergusson (2018) might have switched towards being in favour of the technology. This might, however, be due to the fact that VAR has been a part of football for a few years now, and it is evident that it is here to stay. Therefore, fans might rather just accept it for what it is and not waste any energy on protesting the technology.

Another study that measured fans' perceptions towards decision-aid technology was Stoney and Fletcher (2020). These authors explored how the use of TMO technology affected the experience of in-stadium fans in Rugby Union. Although our survey is not exclusive to in-stadium fans, some of the perceptions can be compared. In Stoney and Fletcher (2020), rugby fans stated that their in-stadium experience would be enhanced if they were better informed during TMO decisions. These findings are supported in this study, with the finding that fans displayed positive perceptions towards having big screens for VAR reviews present to keep them thoroughly informed on what is happening. Although a different sport, the in-stadium experience should be comparable across sports, as the sport fans have a different range of needs and wants, regardless of which sport they follow (Samra and Wos 2014).

Both Winand and Fergusson (2018) and Stoney and Fletcher (2020) did not report any difference in opinion between age groups. By contrast, the present study unveiled significant differences between age groups in 10 out of 15 items. Overall, the findings were supportive of the younger age groups being more in agreement of using VAR than older age groups, consistent with the technology-driven nature of their generation (Yim et al. 2021). However, there were exceptions, with older age groups showing more positive perceptions towards enjoyment of goals with VAR, as well as the use of VAR post-match to penalise players/managers who had done something wrong.

\subsection{Implications}

Implications from this study include recommendations about how VAR can be used further in the EPL. The results show that the highest agreements from fans were that: VAR should be used to assist in situations where Hawk-Eye's GLT fails to perform its tasks; VAR teams should be expanded to include more than one expert referee; big screens should be installed in every stadium; the on-field referee should always review VAR evidence when a potentially match-changing decisions must be made; the way VAR judges offsides should undergo a change. The EPL might consider these items as priorities upon which to act when considering the impact of VAR on fans. Nevertheless, they might encounter certain perceptions that can counterbalance the need for change.

Making big screens mandatory for EPL clubs might be crucial in ensuring fan enjoyment. Yet, it is important to consider that fans will have different experiences over the course of a season depending on the team they support. For the 19/20 season, Liverpool's Anfield and Manchester United's Old Trafford were the only two stadiums without big screens (Sky Sports 2019a). Although the participants agreed that screens should be mandatory, some participants may be fans of Liverpool or Manchester United and might not want to see their stadium undergo drastic changes. By contrast, other supporters of the same two teams may feel that their experience was worsened due to the lack of big screens during VAR reviews. It would certainly make sense for arguably the two biggest clubs in English football to do what they can to aid in-stadium fans in getting information during VAR checks. This would be consistent with the findings of Stoney and Fletcher (2020) on how 
fans report having a worse experience when they are not getting information when video evidence is being reviewed. However, it is important to note that the inclusion criteria for this study did not include fans having to frequently attend games. This means that a large portion of the sample might be attending games less or more frequently. The results of this item also found evidence of younger fans being significantly more positive towards screens than older age groups, although all groups were generally positive. These findings imply that the EPL need to consider future consumers when developing recommendations and regulations. The young age groups of this study will be the ones attending stadiums for the next decades, and their perceptions are likely to be passed on to younger generations (Šramová 2017). If attending games does become less enjoyable due to lack of information in-stadium, people might choose to watch games from home.

Perceptions towards how VAR is used to assess offside situations show that the current system does not function optimally in the eyes of the fans. However, it must be acknowledged FIFA's (Fédération Internationale de Football Association) stated intent on changing the VAR protocol for the EPL. This became evident in early August of 2020 when they passed a new protocol which addressed multiple concerns. This protocol includes intentions of: increasing the on-field referee's use of the review area; enforcing the rules of penalty kicks by retaking saved penalties if the goalkeeper is off his line or a player is inside the box before the kick is taken; encouraging linesmen to keep their flags down for offside situations that are not crystal-clear, to avoid ruining potential goal-scoring opportunities (Premier League 2020). This means that some of the implications from this study are already in the process of being changed. It shows that its findings are consistent with observations FIFA have done themselves. Additionally, the results showed that fans are towards a neutral stance on the negative side when asked if VAR should be used for more than just clear and obvious errors. These results suggest that FIFA should not add more parameters for VAR. This seems like the way to go in terms of keeping VAR simple and to avoid unnecessary confusion for referees, fans, players, and managers, as it has proven to do on numerous occasions in its debut season in the EPL.

Even though fans feel that VAR takes up a bit too much time of an EPL game, the perceptions towards how the tool is used carry more weight for fans. This should be considered important for FIFA and the EPL in developing VAR further. It is, however, important to note that these findings only represent one stakeholder group, being the fans. Organisations like FIFA and the EPL will rely on feedback from more than one group of stakeholders when developing VAR further. However, with fans being the stakeholders that pay for match tickets, merchandise and television subscriptions, their opinions should be deemed very important when considering changes to the game of football.

\subsection{Limitations and Directions for Future Research}

The choice of conducting a quantitative survey to create generalisations of a population was considered to be the best method for this study. However, the ability to answer some of the questions explored in the results and discussion sections was limited due to the nature of the study. These questions would undoubtedly provide more immersive results through qualitative interviews where fans could answer more freely. Another limitation might have been the wording on certain questions, which were intended to be linked to each other. This might have happened with items three and four in Table 1, which were intended to be linked through measuring perceptions towards usage of VAR monitors by on-field referees and time consumption with VAR. However, it is recognised that the question on usage of VAR monitors could have included a note on time consumption to establish a link between the questions. Future researchers should consider this if they want to compare these factors.

Another limitation of this study was the timing of the project. Data collection commenced during COVID-19, and none of the EPL clubs allowed for fans in-stadium during the time of data collection. It was evident during this time that fans wanted to be given the opportunity to visit stadiums again. These feelings might have overshadowed some 
of the negative perceptions towards VAR at the time. Lack of tracking of geographical location of participants was also identified as a limitation. Participants were recruited through social media, and geographical location was not a part of the inclusion criteria. This means that the results could not be compared based on nationality or geographical location, which might have shown certain differences. The social media post included an invite to the survey and was shared in English and Norwegian on Twitter, as well as in both English and Norwegian Facebook groups dedicated to EPL fans. This means that a large portion of the sample may have consisted of Norwegian and English fans. Yet, is not possible to say for certain due to most of the participants being recruited via Twitter where there were no geographical filters present. Future research should include sample groups based on specific geographical locations or include a question where respondents answer their nationality to make such comparisons possible. This also applies to gender to observe whether there are any significant differences between different genders.

The final limitation was that the only stakeholder group explored in this study was the fans. Other key stakeholders include players and managers. A recent study has found that managers are more likely to publicly agree with VAR decisions when they favour their club, while they often question or disagree with VAR decisions when they go against their club (Chen and Davidson 2021). Future research should include these stakeholders to measure for differences. Those stakeholders might have a completely different experience than fans due to their ability to communicate with the team of referees during games and receive information. In other words, it should be deemed fair to assume that a study on the different actors of the game would provide a more immersive look into the subject of VAR.

Supplementary Materials: The following are available online at https:/ / www.mdpi.com/article/10 $.3390 /$ jrfm14120573/s1, Table S1. Survey items.

Author Contributions: Conceptualisation, T.H.; methodology, T.H. and N.S.; software, T.H. and N.S.; validation, T.H. and N.S.; formal analysis, T.H.; investigation, T.H.; resources, T.H.; data curation, T.H.; writing—original draft preparation, T.H.; writing—review and editing, N.S. and T.H.; visualisation, T.H. and N.S.; supervision, N.S.; project administration, T.H. and N.S.. All authors have read and agreed to the published version of the manuscript.

Funding: This research received no external funding.

Institutional Review Board Statement: The study was conducted according to the guidelines of the Declaration of Helsinki and approved via EthOS, the ethical process in place at Manchester Metropolitan University (protocol code 24049, date of approval 22 June 2020).

Informed Consent Statement: Informed consent was obtained from all subjects involved in the study.

Data Availability Statement: The data presented in this study are available as supplementary material.

Acknowledgments: The authors thank Manchester Metropolitan University for having provided them with the opportunity to conduct this research. There is no specific funding associated to it. All errors are the authors' own.

Conflicts of Interest: The authors declare no conflict of interest.

\section{References}

Andrew, Damon P. S., Paul M. Pedersen, and Chad D. McEvoy. 2020. Research Methods and Design in Sport Management, 2nd ed. Champaign: Human Kinetics, pp. 85-89.

Augste, Claudia, and Ole Cordes. 2016. Game stoppages as a tactical means in soccer: A comparison of the FIFA World Cups ${ }^{\mathrm{TM}} 2006$ and 2014. International Journal of Performance Analysis in Sport 16: 1053-64. [CrossRef]

BBC. 2018. "Comical" \& "embarrassing": Reaction to VAR. BBC Sport, March 1. Available online: https://www.bbc.com/sport/ football/43234569 (accessed on 29 October 2021).

BBC. 2019. VAR "should not be too forensic": Football law-makers set to issue guidance. BBC Sport, December 30. Available online: https:/ / www.bbc.com/sport/ football/50944416 (accessed on 29 October 2021).

BBC. 2020. VAR: Wrong penalty decisions in all Thursday games, Match of the Day told. BBC Sport, July 10. Available online: https:/ / www.bbc.com/sport/football/53357841 (accessed on 29 October 2021). 
Bell, Emma, Alan Bryman, and Bill Harley. 2019. Business Research Methods. Oxford: Oxford University Press.

Chen, Ryan, and Nicholas P. Davidson. 2021. English Premier League manager perceptions of video assistant referee (VAR) decisions during the 2019-2020 season. Soccer E Society, 1-12. [CrossRef]

Cooper, I. Diane, and Timothy P. Johnson. 2016. How to use survey results. Journal of the Medical Library Association 104: 174-77. [CrossRef] [PubMed]

Da Silva, Edson Coutinho, and Alexandre Luzzi Las Casas. 2017. Sport fans as consumers: An approach to sport marketing. British Journal of Marketing Studies 5: 36-48.

Duffy, Bobby, Kate Smith, George Terhanian, and John Bremer. 2005. Comparing data from online and face-to-face surveys. International Journal of Market Research 47: 615-39. [CrossRef]

Dwyer, Brendan, Carrie LeCrom, and Gregory P. Greenhalgh. 2016. Exploring and measuring spectator sport fanaticism. Communication $\mathcal{E}$ Sport 6: 58-85. [CrossRef]

Errekagorri, Ibai, Julen Castellano, Ibon Echeazarra, and Carlos Lago-Peñas. 2020. The effects of the Video Assistant Referee system (VAR) on the playing time, technical-tactical and physical performance in elite soccer. International Journal of Performance Analysis in Sport, 1-10. [CrossRef]

FRA. n.d. Age of Majority. European Union Agency for Fundamental Rights. Available online: https://fra.europa.eu/en/publication/ 2017/mapping-minimum-age-requirements/age-majority (accessed on 29 October 2021).

Han, Bo, Qiu Chen, Carlos Lago-Peñas, Changquan Wang, and Tianbiao Liu. 2020. The influence of the video assistant referee on the Chinese Super League. International Journal of Sports Science E Coaching 15: 662-68. [CrossRef]

Hawk-Eye. n.d. Football. Hawk-Eye Innovations. Available online: https:/ /www.hawkeyeinnovations.com/sports/football (accessed on 29 October 2021).

Hunt, Kenneth A., Terry Bristol, and R. Edward Bashaw. 1999. A conceptual approach to classifying sports fans. Journal of Services Marketing 13: 439-52. [CrossRef]

IFAB. 2018. Historic step for greater fairness in football. IFAB, March 3. Available online: https://www.theifab.com/news/historicstep-for-greater-fairness-in-football (accessed on 29 October 2021).

Janzen, Rich, Nghia Nguyen, Alethea Stobbe, and Liliana Araujo. 2015. Assessing the value of inductive and deductive outcome measures in community-based programs: Lessons from the City Kidz evaluation. The Canadian Journal of Program Evaluation, 30. [CrossRef]

Johnson, Dale. 2020. How VAR decisions affected every Premier League club in 2019-20. ESPN, July 26. Available online: https:/ / www.espn.com/soccer/english-premier-league/story/3929823/how-var-decisions-have-affected-every-premier-league-club (accessed on 29 October 2021).

KNVB. n.d. Video Referee. KNVB. Available online: https:/ /www.knvb.com/themes/new-laws-of-the-game/refereeing-2.0/videoreferee (accessed on 29 October 2021).

Lago-Peñas, Carlos, Rey Ezequiel, and Kalén Anton. 2019. How does Video Assistant Referee (VAR) modify the game in elite soccer? International Journal of Performance Analysis in Sport 19: 646-53. [CrossRef]

Ludvigsen, Jan Andre Lee. 2020. The Premier League-globalization nexus: Notes on current trends, pressing issues and inter-linked “-ization" processes. Managing Sport and Leisure 25: 37-51. [CrossRef]

Martin, Richard. 2018. VAR disrupts flow of game, says Barca's Suarez. Reuters, September 5. Available online: https://www. reuters.com/article/uk-soccer-spain-fcb-suarez/var-disrupts-flow-of-game-says-barcas-suarez-idUKKCN1LL1FI (accessed on 29 October 2021).

Mastromartino, Brandon, Wen-Hao Winston Chou, and James J. Zhang. 2017. The passion that unites us all: The culture and consumption of sports fans. In Exploring the Rise of Fandom in Contemporary Consumer Culture. Edited by Cheng Lu Wang. Pennsylvania: IGI Global, pp. 52-70. [CrossRef]

Nafziger, James A. R. 2004. Avoiding and resolving disputes during sports competition: Of cameras and computers. Marquette Sports Law Review 15: 13-27.

Nlandu, Tamba. 2012. The fallacies of the assumptions behind the arguments for goal-line technology in soccer. Sport, Ethics and Philosophy 6: 451-66. [CrossRef]

Olson, Katherine E., Marita A. O'Brien, Wendy A. Rogers, and Neil Charness. 2010. Diffusion of technology: Frequency of use for younger and older adults. Ageing International 36: 123-45. [CrossRef] [PubMed]

Ponto, Julie. 2015. Understanding and evaluating survey research. Journal of the Advanced Practitioner in Oncology 6. [CrossRef]

Premier League. 2019a. Video Assistant Referees Explained IVAR. Premier League, July 25. Available online: https://www. premierleague.com/VAR (accessed on 31 May 2020).

Premier League. 2019b. VAR: Clear and Obvious Explained. Premier League, July 30. Available online: https://www.premierleague. com/news / 1297392\#: \{\}:text=30\%20Jul\%202019\&text=VAR\%20can\%20be\%20used\%20to (accessed on 29 October 2021).

Premier League. 2020. Statement on VAR and Substitute Players. Premier League, August 6. Available online: https://www. premierleague.com/news/1749286 (accessed on 29 October 2021).

Queirós, André, Daniel Faria, and Fernando Almeida. 2017. Strengths and limitations of qualitative and quantitative research methods. European Journal of Education Studies 3: 369-87.

Revilla, Melanie A., Willem E. Saris, and Jon A. Krosnick. 2013. Choosing the number of categories in agree-disagree scales. Sociological Methods \& Research 43: 73-97. [CrossRef] 
Samra, Balwant, and Anna Wos. 2014. Consumer in sports: Fan typology analysis. Journal of Intercultural Management 6: $263-88$. [CrossRef]

Singh, Harjass. 2012. In search of a level playing field: Rules, morals and the jurisprudence of sport. The International Journal of Sport and Society 3: 81-90. [CrossRef]

Sky Sports. 2019a. Premier League Clubs to Show VAR Replays in Stadium. Sky Sports, June 5. Available online: https:/ / www.skysports. com/football/news/11661/11735685/premier-league-clubs-to-show-var-replays-in-stadium (accessed on 29 October 2021).

Sky Sports. 2019b. VAR: Premier League Referee Chief Mike Riley Admits four Mistakes This Season. Sky Sports, September 12. Available online: https: / www.skysports.com/football/news/11095/11807734/var-premier-league-referee-chief-mike-rileyadmits-four-mistakes-this-season (accessed on 29 October 2021).

Spitz, Jochim, Johan Wagemans, Daniel Memmert, A. Mark Williams, and Werner F. Helsen. 2021. Video assistant referees (VAR): The impact of technology on decision making in association football referees. Journal of Sports Sciences 39: 147-53. [CrossRef]

Šramová, Blandína. 2017. Children's consumer behavior. In Consumer Behavior Practice Oriented Perspectives. London: IntechOpen. [CrossRef]

Stoney, Emma, and Thomas Fletcher. 2020. "Are fans in the stands an afterthought?": Sports events, decision-aid technologies, and the television match official in rugby union. Communication $\mathcal{E}$ Sport. [CrossRef]

Svantesson, Dan Jerker B. 2014. Could technology resurrect the dignity of the FIFA World Cup refereeing? Computer Law \& Security Review 30: 569-73. [CrossRef]

The FA. 2012. Extracts from the FA report on the Luis Suárez Patrice Evra racism case. The Guardian, January 1. Available online: https:/ / www.theguardian.com/football/2012/jan/01/fa-report-luis-suarez-patrice-evra (accessed on 29 October 2021).

Ugondo, Peter Iorper, and Maggai Tsokwa. 2019. Interpreting video assistant referee and goal-line technology communication: The pitch-based referees perspectives. International Journal of Trend in Scientific Research and Development 3: 1058-62. [CrossRef]

Vaportzis, Eleftheria, Maria Giatsi Clausen, and Alan J. Gow. 2017. Older adults perceptions of technology and barriers to interacting with tablet computers: A focus group study. Frontiers in Psychology 8: 1687. [CrossRef] [PubMed]

Veal, Anthony James. 2018. Research Methods for Leisure and Tourism, 5th ed. London: Pearson.

Weijters, Bert, Elke Cabooter, and Niels Schillewaert. 2010. The effect of rating scale format on response styles: The number of response categories and response category labels. International Journal of Research in Marketing 27: 236-47. [CrossRef]

Wilkie, Stephanie. 2008. Determinants of home atmosphere in English football: A committed supporter perspective. Journal of Sport Behaviour 31: 312-28.

Winand, Mathieu, and Craig Fergusson. 2018. More decision-aid technology in sport? An analysis of football supporters' perceptions on goal-line technology. Soccer $\mathcal{E}$ Society 19: 966-85. [CrossRef]

Wolfson, Sandy, Delia Wakelin, and Matthew Lewis. 2005. Football supporters' perceptions of their role in the home advantage. Journal of Sports Sciences 23: 365-74. [CrossRef] [PubMed]

Yim, Brian H., Kevin K. Byon, Thomas A. Baker, and James J. Zhang. 2021. Identifying critical factors in sport consumption decision making of millennial sport fans: Mixed-methods approach. European Sport Management Quarterly 21: 484-503. [CrossRef] 